\title{
Large eddy simulation of flame propagation from leakage of naphtha in a cracking furnace
}

\author{
J. Ahn ${ }^{1} \&$ S. Jang ${ }^{2}$ \\ ${ }^{1}$ School of Mechanical Engineering, Kookmin University, Korea \\ ${ }^{2}$ Department of Mechanical Engineering, Graduate School, \\ Kookmin University, Korea
}

\begin{abstract}
In the petrochemical plant, the flammable materials are processed so that there exists risk of fire and/or explosion accidents. They come from the leakage of raw materials or petrochemical products from tubes or tanks. If the leakage occurs inside a reacting furnace with high temperature and pressure, it should lead to serious casualty. To prevent accidents or minimize the damage from these accidents, one should understand the behaviour of flame from a ruptured pipe inside the furnace. In the present study, a large eddy simulation was conducted to investigate flame propagation characteristics from ruptured reactor tube in a naphtha cracking furnace to understand flame propagation pattern and heat and mass transfer inside the furnace to generate secondary accident. Fire Dynamics Simulator (FDS) was used for the simulation and the number of grid points were around 700,000 . The cracking furnace has burners at the bottom part to heat the reactor tubes and combustion gas flows out at the exit located on top of the furnace. Ruptured part was made on the reactor tube with the dimension of $10 \%$ of tube diameter and placed near the burner. Leakage flame starts from the ruptured part and evolved to be merged with the fire from burners and generate separated flamelets. Temperature inside the furnace rises higher than the safe temperature of the pipe material, which raises the possibility of successive rupture of neighbour tubes. Unburned hydrocarbons flow out of the vent, which could lead to secondary accidents.

Keywords: petrochemical plant, fire, combustion.
\end{abstract}




\section{Introduction}

Chemical plants in Korea have increased rapidly since the late 1960s. As a result, the number plants including refineries in South Korea has reached the world's top 10 [1] As many of them have operated for over 10 years, it is becoming increasingly to suffer deterioration in the long-term use [2]. So, interest in plant life and reliability evaluation has recently been increasing accordingly. Korean petrochemical plant accidents have occurred most frequently at the pipe line. The reformer is operated at a high temperature between $500^{\circ} \mathrm{C}$ and $1200^{\circ} \mathrm{C}$ and a high pressure over $1 \mathrm{MPa}$. This condition is most extreme environments in petrochemical plants. Thus, it may lead to a serious accident.

In this study, the numerical simulation on flame propagation of the gas leak on pipe wall is conducted. The results would be utilized to understand detailed physics of flame propagation and to develop measures for minimizing the damage caused by an accident.

Table 1: Geometric dimensions and flow conditions.

\begin{tabular}{|c|c|}
\hline Length & $11.8 \mathrm{~m}$ \\
\hline Width & $5.4 \mathrm{~m}$ \\
\hline Height & $12.3 \mathrm{~m}$ \\
\hline Burner & 8 \\
\hline Burner fuel gas & Methane \\
\hline Burner fuel flow rate & $0.125 \mathrm{\ell} / \mathrm{sec}$ \\
\hline Leak point & 1 \\
\hline Leakage gas & Ethylene \\
\hline Leakage gas flow rate & $4.2 \ell / \mathrm{sec}$ \\
\hline Number of meshes & 701,202 \\
\hline
\end{tabular}

Table 2: Numerical analysis model.

\begin{tabular}{|c|c|}
\hline Program & FDS (Fire Dynamics Simulator) \\
\hline Numerical Technique & LES \\
\hline Scheme & Explicit \\
\cline { 2 - 2 } & Second order \\
\hline Reaction modeling & Eddy dissipation concept \\
\cline { 2 - 2 } & Single step \\
\hline Radiation model & Wide-band \\
\cline { 2 - 2 } & Deardorff eddy viscosity model \\
\hline Sub grid scale model & Lumped species \\
\hline Mass and species transport & Wall function \\
\hline Wall Boundary Condition & Constant \\
\hline Turbulent Schmidt Number & Constant \\
\hline Turbulent Prandtl Number &
\end{tabular}


(a)

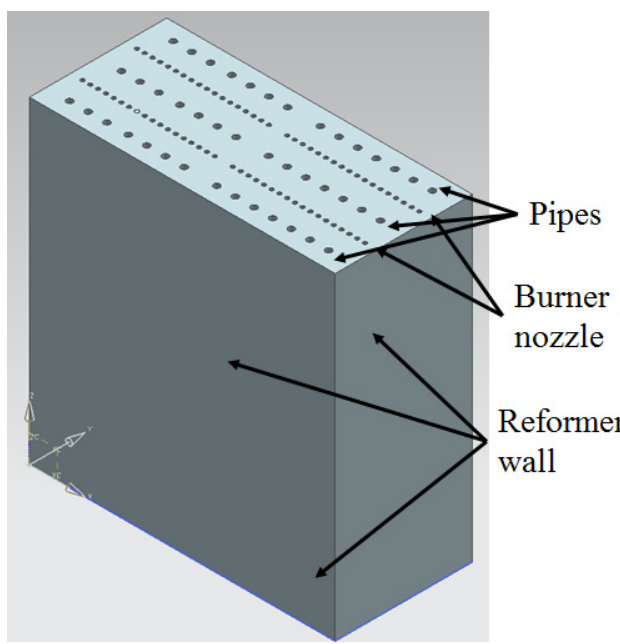

(c)

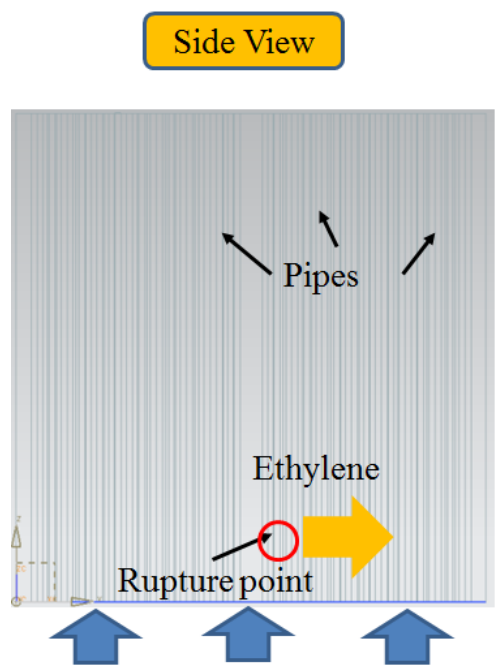

(b)

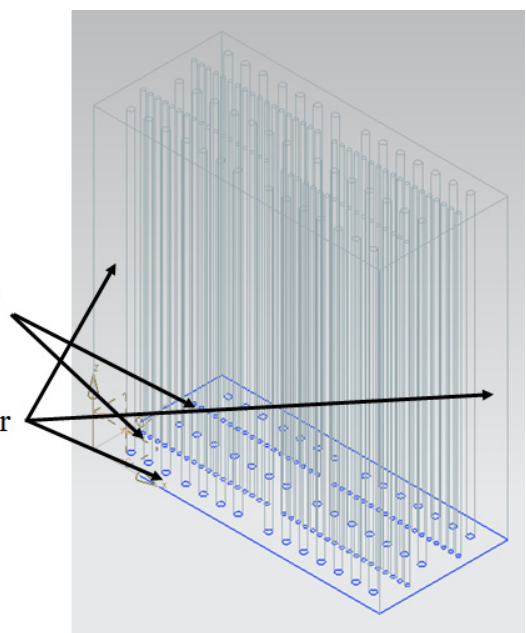

(d)

(e)

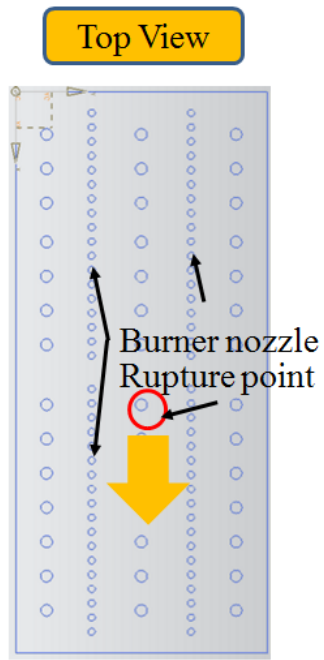

Figure 1: Computational domain (reformer internal geometry): (a) reformer exterior, (b) reformer interior, (c) side view, (d) top view, (e) front view.

Based on the statistics regarding accident at petrochemical plant, naphtha reforming furnace has selected as the problem. Numerical analysis was performed on the flame propagation of the gas leak accident from damaged inner pipe. 
Numerical analysis was performed using Large Eddy Simulation (LES) of Fire Dynamics Simulator (FDS) code.

(a)

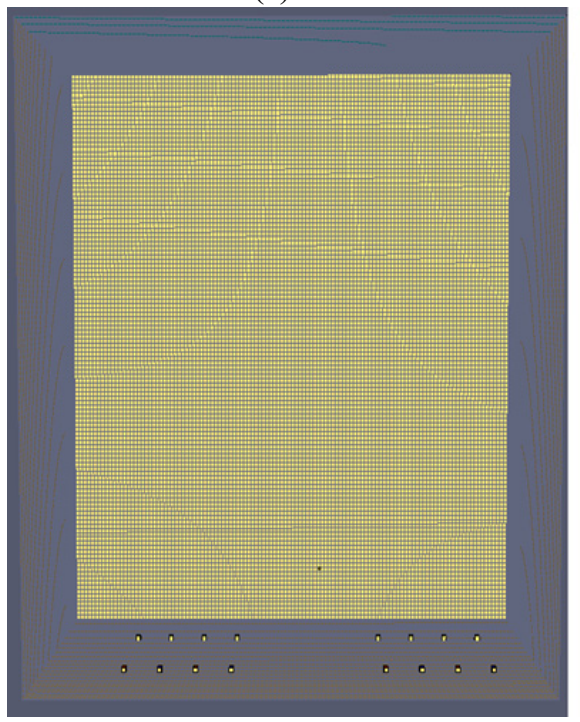

(b)

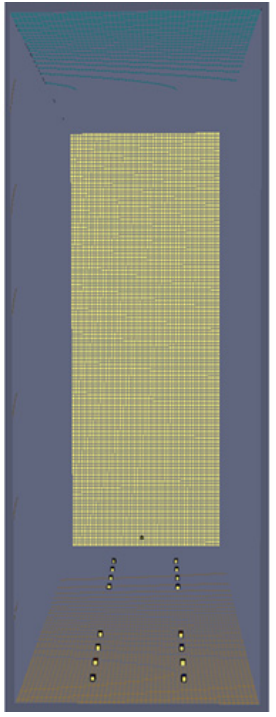

(c)

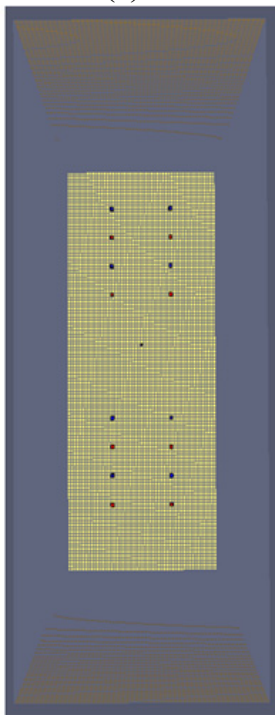

Figure 2: $\quad$ Grid system (701,202 meshes) (a) Side view, (b) Front view, (c) Top view.

Firstly, flame propagation from the leakage point is investigated. Computational domain includes the whole furnace in order to check whether there might be successive destruction of the walls or neighbour tubes. In order to do, the pressure, temperature, velocity and distribution of the reactants and products species are investigated.

\section{Numerical simulation}

Computational domain is the furnace that includes naphtha cracking tubes and burners as shown in Fig. 1. Detailed geometries and dimensions were determined based on industrial data. The furnace size is $11.8 \mathrm{~m} \times 5.4 \mathrm{~m} \times 12.3 \mathrm{~m}$, it has 8 burners. Fuel flow rate to be set as $0.125 \mathrm{l} / \mathrm{sec}$ and rupture section of the tube is made as one point at the bottom part of the furnace, where the burner is closely located. Gas leakage flow rate is assumed to be $4.2 \mathrm{l} / \mathrm{sec}$. Detailed dimensions and flow conditions are shown in Table 1. Burner fuel is assumed to be methane, which takes around 90\% natural gas used in Korea.. 
(a)

\section{$0.5 \mathrm{sec}$}

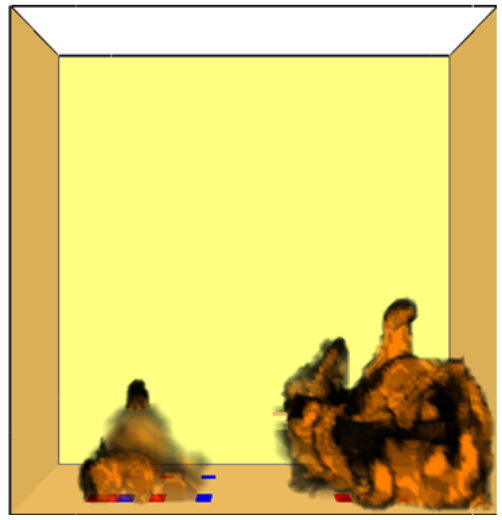

(c)

\section{$5 \mathrm{sec}$}

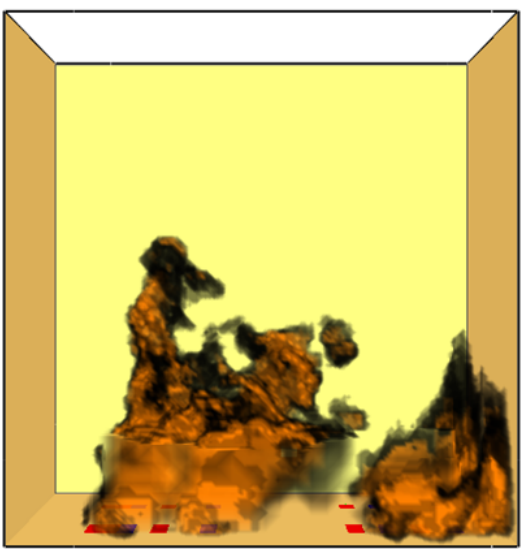

(b)

\section{$2 \mathrm{sec}$}

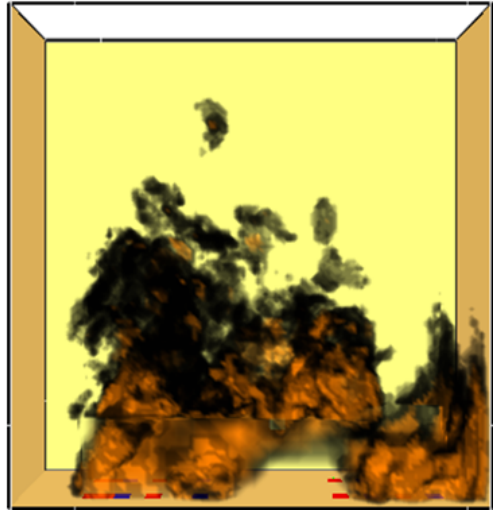

(d)

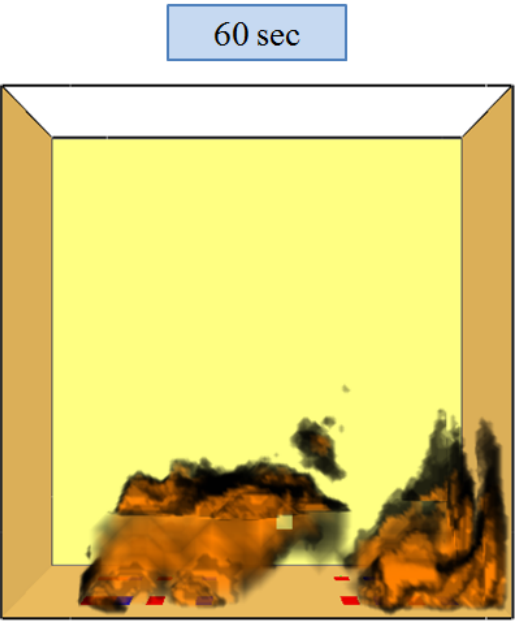

Figure 3: Flame propagation images (inside reformer, methane and ethylene combustion) (a) 0.5 seconds, (b) 2 seconds, (c) 5 seconds, (d) 60 seconds (End).

The leakage gas is assumed to be ethylene, which is an intermediate product of the cracking process. Numerical simulation is conducted using FDS, which supports multiple fuel combustion. A pre-test is carried out to examine the usage of FDS code designed for low Mach number and it is proved to be applicable with the maximum Mach number within 0.3. 
(a)

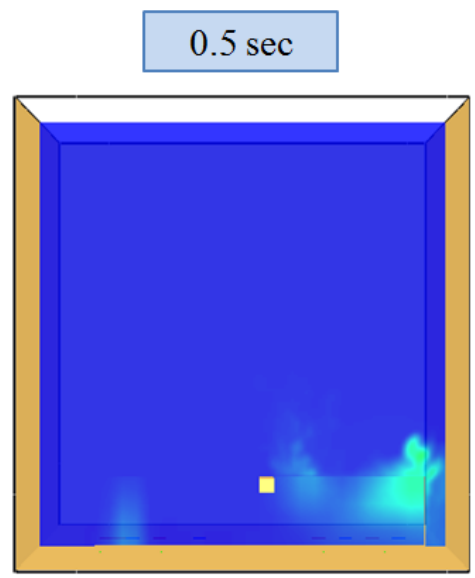

(c)

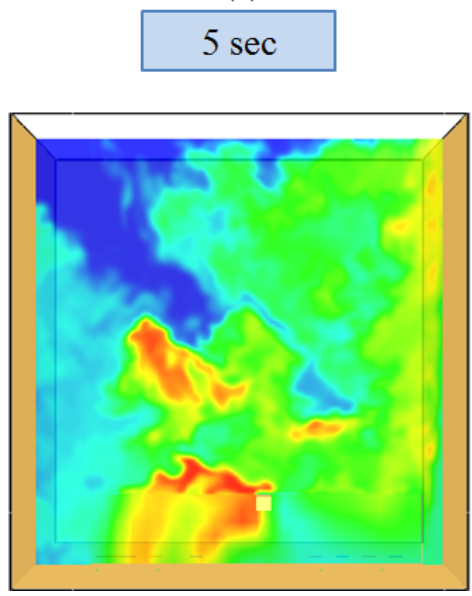

(b)

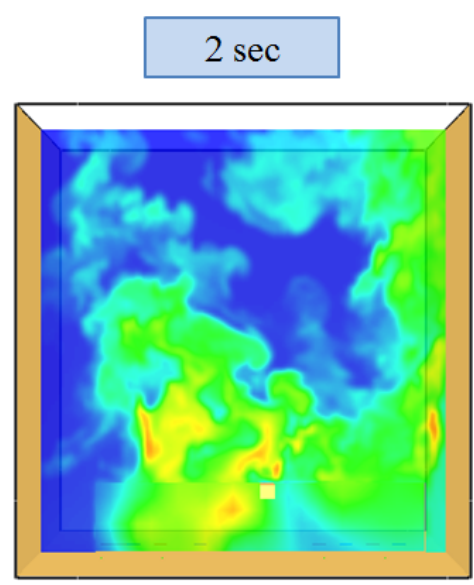

(d)

\section{$60 \mathrm{sec}$}

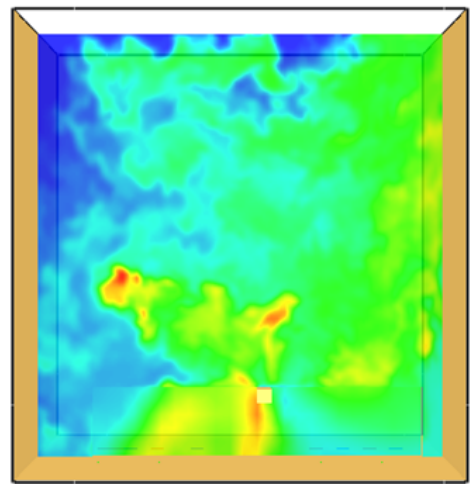

Temperature $\left({ }^{\circ} \mathrm{C}\right)$

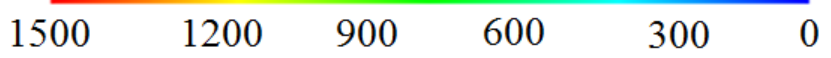

Figure 4: Temperature contours with time (a) 0.5 seconds, (b) 2 seconds, (c) 5 seconds, (d) 60 seconds.

Flue gas outlet is located at the upper part of the furnace. The time of gas leakage is set to be 60 seconds, which is a typical shut-off time for an accident. Grid system shown in Fig. 2. FDS is a spectral code, which allows only Cartesian grid system. Cartesian mesh, composed of 701,202 hexahedron cells, is used for this study. 
(a)

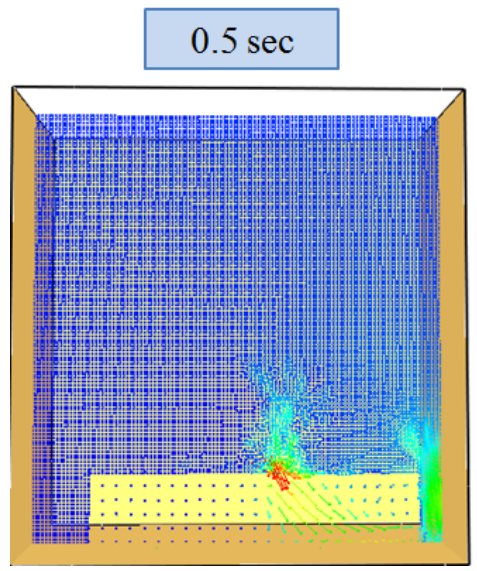

(c)

\section{$5 \mathrm{sec}$}

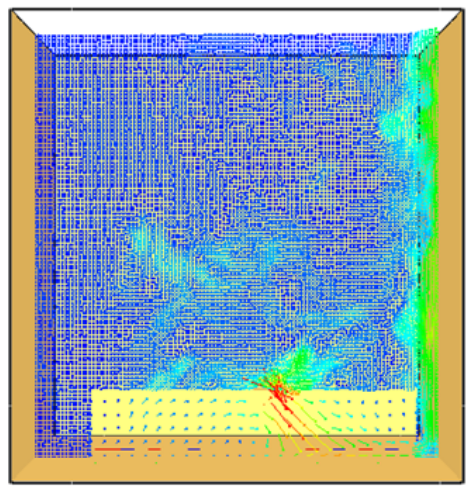

(b)

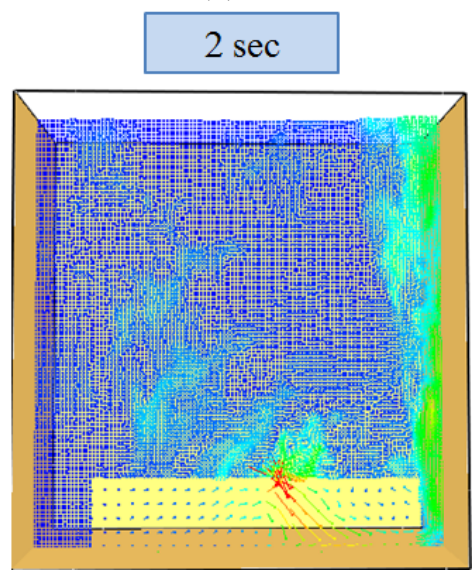

(d)

\section{$60 \mathrm{sec}$}

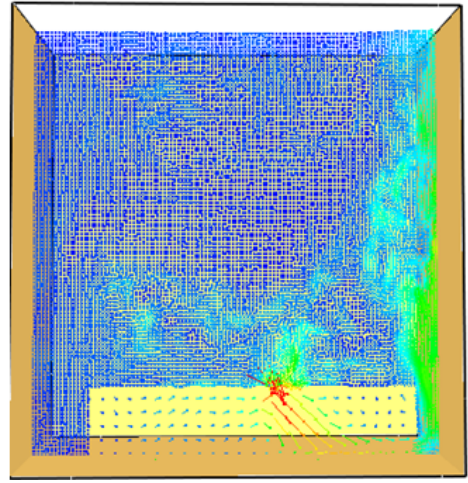

Velocity $(\mathrm{m} / \mathrm{s})$

\section{$\begin{array}{llllll}89 & 71.4 & 53.9 & 36.3 & 18.8 & 1.2\end{array}$}

Figure 5: Velocity vectors with time (a) 0.5 seconds, (b) 2 seconds, (c) 5 seconds, (d) 60 seconds.

A standard wall function is used for wall boundary condition. Thermal radiation was considered adopting a wide band model [3]. Numerical details including models are summarized in Table 2. Analysis is performed in the 3D domain. 


\section{Results and discussion}

In the beginning, the flame starts from the burner and well anchored there. As ethylene is leaked at the rupture point and ignited, the flame is enlarged. Then, some part of the flame is separated to evolve as a lifted.

(a)

$$
0.5 \mathrm{sec}
$$

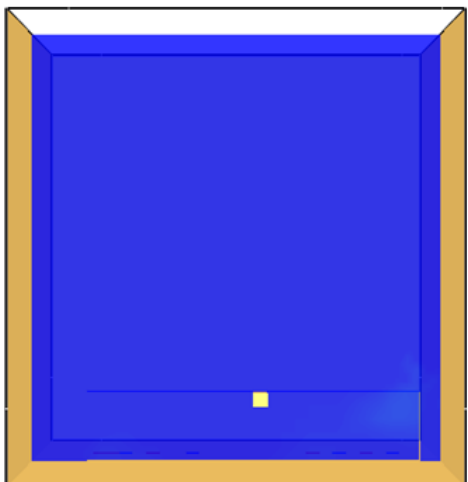

(c)

\section{$5 \mathrm{sec}$}

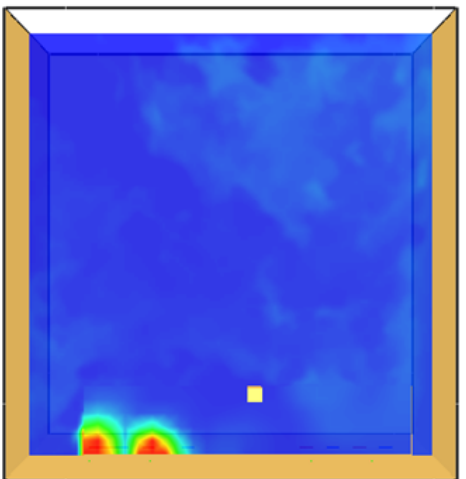

(b)

\section{$2 \mathrm{sec}$}

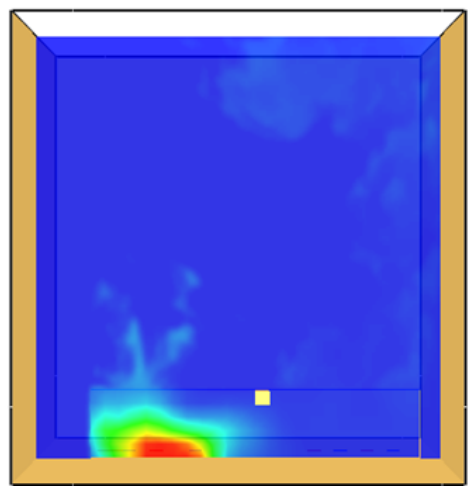

(d)

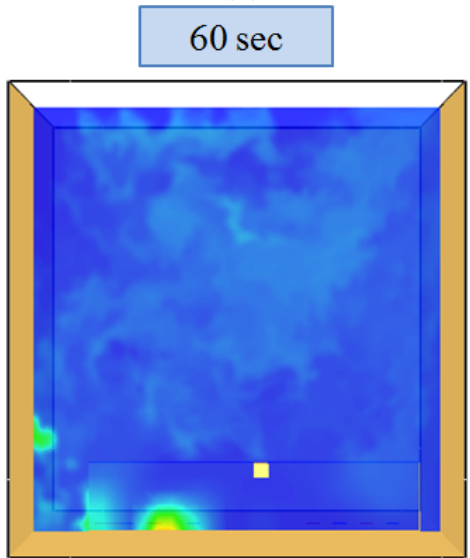

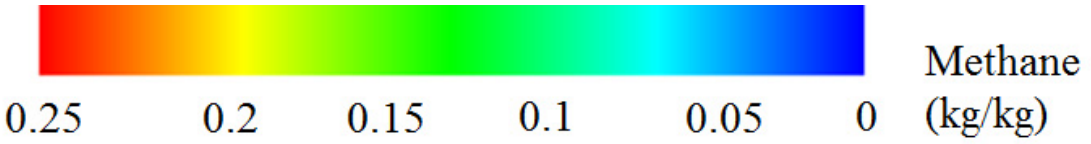

Figure 6: Methane distributions with time (a) 0.5 seconds, (b) 2 seconds, (c) 5 seconds, (d) 60 seconds. 
(a)

\section{$0.5 \mathrm{sec}$}

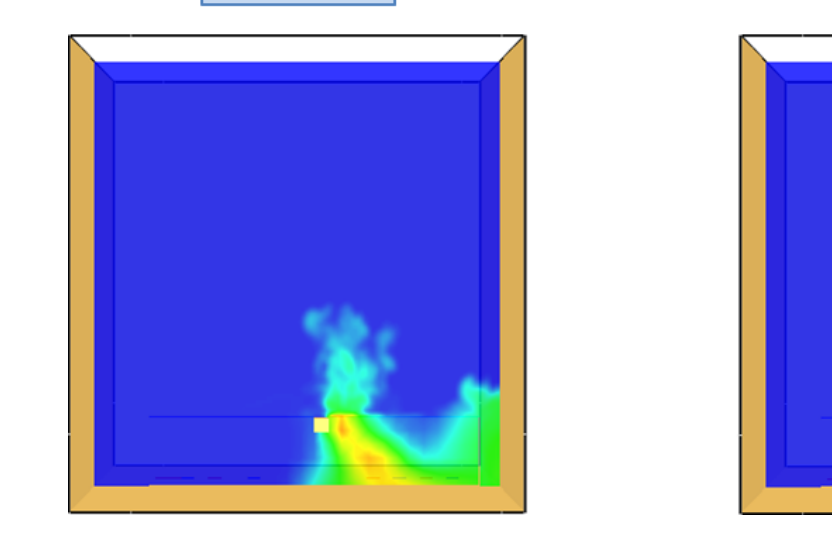

(c)

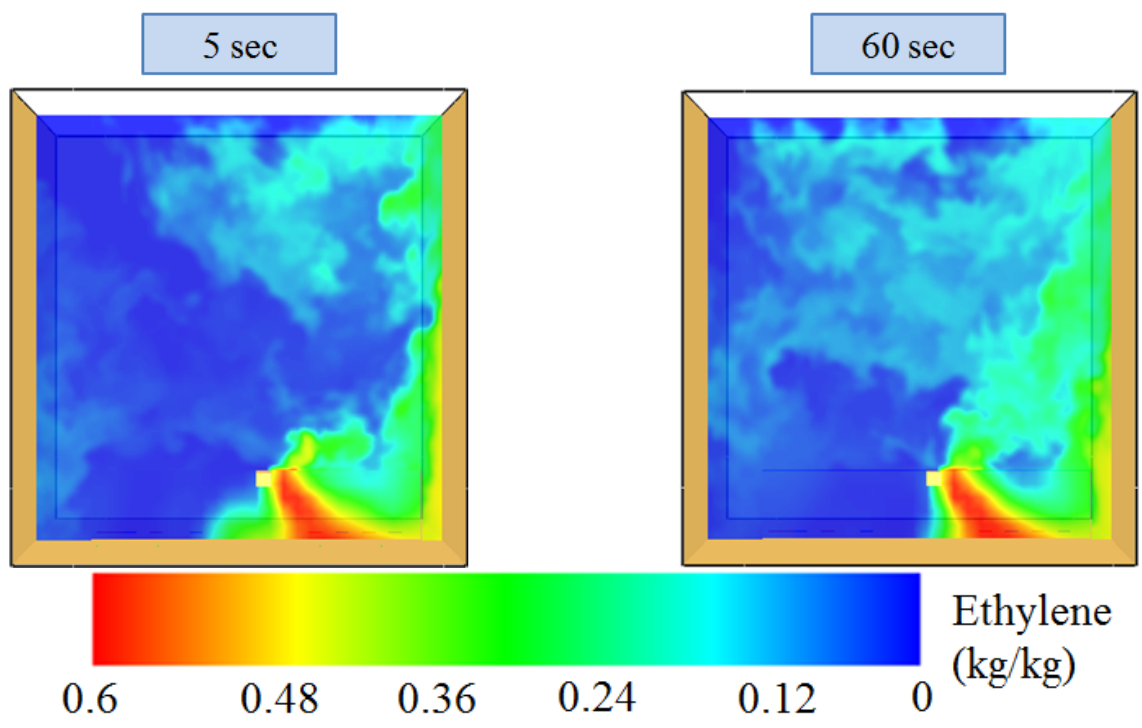

(b)

\section{$2 \mathrm{sec}$}

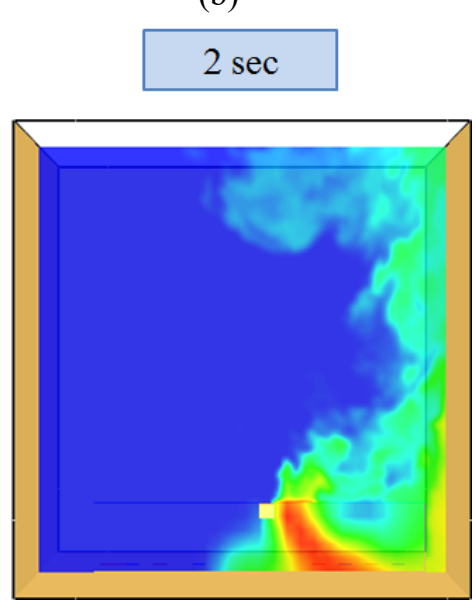

(d)

)

$(\mathrm{d})$

Figure 7: Ethylene distributions with time (a) 0.5 seconds, (b) 2 seconds, (c) 5 seconds, (d) 60 seconds.

After five seconds, the flame shape is maintained to be similar until the end of simulation. The shape evolutions of the flames are illustrated in Fig. 3. Inner wall of the reformer is made of concrete. Therefore, thermal stress also gives a significant effect on the damage of the wall. In addition, safe temperature of the reformer inner pipe is known as $1093^{\circ} \mathrm{C}$. So, it is necessary to check the temperature field inside the furnace if the maximum temperature rises above 
$1093^{\circ} \mathrm{C}$. Temperature distributions from $0.5,2,5$ and 60 seconds are shown in Fig. 4. Temperature rises as high as $1500^{\circ} \mathrm{C}$ in 5 seconds to raise possibility of successive rupturing neighbour tubes. Velocity vectors are shown in Fig. 5. There exists an upward flow from the rupture point at the initial ignition stage at $0.5 \mathrm{sec}$. After flame is merged in 2 seconds, a large flow structure appears from the rupture point along the furnace wall to the vent. Vortices are shown around flame lets (see Fig. 3), which apply shear to separate them from the main flame.

Species distributions are shown in Figs 6 to 7. Methane contours start to move upward at 2 second and unburned methane is observed throughout the furnace in 60 seconds (Fig. 6). As for the ethylene (Fig. 7), significant amount of unburned part flows out of the furnace after 2 seconds, which raises the possibility of secondary fire or explosion.

\section{Conclusions}

In the present study, a large eddy simulation was conducted for the flame propagation from leakage of naphtha in a cracking furnace. Leakage flame starts from the ruptured part and evolves to be merged with the fire from burners and generate separated flame lets. Temperature inside the furnace rises higher than the safe temperature of the pipe material, which raises the possibility of successive rupture of neighbour tubes. Unburned hydrocarbons flow out of the vent, which could lead to secondary accidents.

\section{Acknowledgements}

This work was supported by the Energy Efficiency \& Resources Core Technology Program of the Korea Institute of Energy Technology Evaluation and Planning (KETEP) granted financial resource from the Ministry of Trade, Industry and Energy, and Republic of Korea (No. 20132010500060)

\section{References}

[1] Kim, T. G., Kim, J. H., Kim, Y. D. and Kim, K. I., Current risk management status of the Korean petrochemical industry, J. Loss Prevention, Vol. 15, pp. 311-318, 2002.

[2] Kim, K. R., Hwang, S. Y. and Kim B. H., A study on the safety management of the petrochemical complex area, J. Korean Institute of Fire Sci. Eng, Vol. 26, No.1, pp. 38-42, 2012.

[3] Seifzadeh Haghighia, S. Rahimpoura, M.R. Raeissia, S. and Dehghania, O., Investigation of ethylene production in naphtha thermal cracking plant in presence of steam and carbon dioxide, Chemical Engineering Journal, Vol. 228, pp. 1158-1167, 2013. 